\title{
PREOPERATIVE CHEMOTHERAPY VERSUS SURGICAL THERAPY ALONE FOR SQUAMOUS CELL CARCINOMA OF THE ESOPHAGUS: A PROSPECTIVE RANDOMIZED TRIAL
}

Simon Law, MB, BChir, FRCSEd Manson Fok, MB, BS, FRCSEd Selwyn Chow*

Kent-Man Chu, MB, BS, FRCSEd John Wong, PhD, MD, FRACS, FACS
Objective: This study investigated the role of preoperative chemotherapy in squamous cell cancer of the esophagus. Methods: A prospective randomized trial was undertaken in 147 patients: 74 received preoperative chemotherapy comprising cisplatin and 5 -fluorouracil and 73 had surgical therapy alone. End points were cancer and therapy-related deaths. Results: Sixty-six patients $(89 \%)$ in the chemotherapy group underwent resection compared with $69(95 \%)$ in the control group ( $p=$ not significant). Of the 60 patients who had resection after completing the chemotherapy program, $35(58 \%)$ had a significant response, of whom four (6.7\%) had a complete pathologic response. Postoperative mortality rates were $8.3 \%$ and $8.7 \%$ in the chemotherapy and control groups, respectively ( $p=$ not significant). Significant downstaging was evident with chemotherapy; curative resections were possible in $67 \%$ of these patients compared with $35 \%$ in the control group $(p=0.0003)$. T3 and T4 tumors were found in $67 \%$ and $91 \%$ of the chemotherapy and control groups, respectively $(p=0.0002)$. The respective figures for N1 disease were $70 \%$ and $88 \%(p=0.009)$. An intent-to-treat analysis of survival showed no significant difference between the two groups. Median survivals were 16.8 and 13 months, respectively $(p=0.17$ ). Of those who completed the chemotherapy and resection, responders fared better than control patients. Median survivals were $\mathbf{4 2 . 2}$ months and 13.8 months, respectively $(p=0.003)$. Median survival $(8.3$ months) was worse for nonresponders than for control patients $(p=0.03)$. The recurrence pattern suggested a significant reduction in locoregional disease with chemotherapy. Conclusions: Preoperative chemotherapy was safe and resulted in significant downstaging and an increased likelihood of curative resection. Survival was not better than that in the surgery-alone group, but responders did fare better than nonresponders. (J Thorac Cardiovasc Surg 1997;114:210-7)
A dvances in anesthesia, risk analysis, and operative techniques have led to modest improvement in the overall prognosis of esophageal cancer during the past decades. ${ }^{1,2}$ This lack of significant improvement is perhaps related to the late stage of presen-

From the Division of Upper Gastrointestinal Surgery, Department of Surgery, The University of Hong Kong, Queen Mary Hospital, Hong Kong.

Received for publication August 29, 1996; revisions requested Feb. 13, 1997; revisions received March 12, 1997; accepted for publication March 13, 1997.

Address for reprints: John Wong, PhD, FRACS, FACS, Department of Surgery, The University of Hong Kong, Queen Mary Hospital, Pokfulam Rd., Hong Kong.

${ }^{*}$ Research assistant.

Copyright () 1997 by Mosby-Year Book, Inc.

$0022-5223 / 97 \$ 5.00+0 \quad \mathbf{1 2 / 1 / 8 1 9 4 6}$ tation of most patients and to the difficulty of achieving an $R_{0}$ resection (absence of residual microscopic and macroscopic disease ${ }^{3}$ ) because of early cancer spread and close proximity of tumor to adjacent mediastinal structures. Studies of disease recurrence patterns have demonstrated that both local and systemic metastases are common., ${ }^{4} \mathrm{Al}-$ though surgery remains the standard treatment for esophageal cancer, a variety of combined modality treatments have been investigated to induce downstaging of tumor, improve local control, treat micrometastases, and ultimately to improve long-term survival. Few controlled clinical trials have been performed. We investigated the role of preoperative chemotherapy in squamous cell carcinoma of the esophagus in a prospective randomized controlled trial. 


\section{Methods}

From December 1989 to January 1995, with approval by the institutional review board, 147 patients with histologic evidence of squamous cell cancer of the thoracic esophagus were randomized after informed consent to have preoperative chemotherapy (chemotherapy group) or immediate surgery (control group). Preoperative tumor staging and assessment of resectability were performed with clinical examination, chest roentgenography, double-contrast barium study, abdominal ultrasonography, and endoscopy and bronchoscopy with flexible scopes. Computed tomography and endoscopic ultrasonography were not readily available and so were not routinely performed. Tumor stages were defined as follows: An early tumor was shorter than $5 \mathrm{~cm}$, produced low-grade obstruction without longitudinal axis deviation or sinus formation on barium contrast studies, and caused no abnormalities on bronchoscopic studies. A moderately advanced tumor was longer than $5 \mathrm{~cm}$ and caused significant obstruction on contrast study. A locally advanced tumor was longer than 5 $\mathrm{cm}$, caused complete obstruction, angulation, or sinuses on barium contrast studies, and/or had a bulge abutting from outside on bronchoscopic examination, with the carina also being widened in some cases.

Patients were excluded from the trial if any of the following findings were present: nonregional lymph node metastases or systemic organ metastases; tumor infiltration into the trachea or bronchi; poor renal function with creatinine clearance less than $1.0 \mathrm{ml} / \mathrm{sec}$ or serum creatinine concentration greater than $130 \mu \mathrm{mol} / \mathrm{L}$; white blood cell count less than $3500 / \mu$ l or granulocyte count less than $1500 / \mu \mathrm{l}$; and platelet count less than $100,000 / \mu \mathrm{l}$. Patients were also excluded if they had a history of cancer, except when these cancers had been treated and had not recurred for at least 5 years.

Chemotherapy regimen. Chemotherapy consisted of two courses of cisplatin and 5-fluorouracil. Patients were hydrated before the start of chemotherapy. Forced diuresis with $20 \%$ mannitol and intravenous fluid was given for the first day. Cisplatin $\left(100 \mathrm{mg} / \mathrm{m}^{2}\right)$ was given as an intravenous infusion over 4 hours on day 1 , followed by an infusion of 5 -fluorouracil ( $500 \mathrm{mg} / \mathrm{m}^{2}$ per day) over days 1 to 5. Appropriate antiemetic medications were prescribed. Chemotherapy was repeated from days 22 to 26 . The tumor was then restaged and the operation was performed on day 42.

Evaluation of response to chemotherapy. The tumors of all patients who had chemotherapy were restaged before surgery. Response was graded as follows: no response-progression or less than $50 \%$ reduction in the size of the tumor, as measured by the product of the longest perpendicular diameters assessed by endoscopic and radiologic studies, or the appearance of new lesions not found at baseline; partial response-more than $50 \%$ reduction in size of tumor measured as just described; complete response-disappearance of tumor on endoscopic and radiologic examination and no other evidence of disease; complete pathologic response-no tumor identified on histologic examination of surgical specimen after surgical resection and no other evidence of disease. Responders were patients who had a partial or complete response, and nonresponders were those with no re- sponse. The side effects of chemotherapy were classified according to the recommendations of the World Health Organization.

Surgical techniques. Most patients had a tumor of the middle third of the esophagus, and our preferred surgical approach was through abdominal and right thoracotomy incisions together with mediastinal lymphadenectomy. In patients with limited cardiopulmonary reserves, a transhiatal resection was performed with a cervical anastomosis. Resection was considered curative when the tumor was confined to the esophagus and the adjacent lymph nodes were either uninvolved or were less than $2 \mathrm{~cm}$ in diameter, discrete, and within the vicinity of the primary tumor. Both the tumor and the adjacent lymph nodes were removed completely. Resection was palliative when the tumor had infiltrated beyond the esophagus into mediastinal organs, with gross lymph node metastases, and when part of the tumor was known or likely to have been left behind after resection. The various surgical techniques have been described previously. ${ }^{6}$. Neither adjuvant chemotherapy nor radiotherapy was given after the operation. Such treatments were only selectively applied when recurrent disease was diagnosed in patients who had good performance status.

Follow-up. Patients were seen monthly for 1 year and then at 3-month intervals. At each follow-up, a complete physical examination was performed. Appropriate investigations including endoscopic, radiologic, and histopathologic examinations were performed as indicated when disease recurrence was suspected. The study end points were cancer and therapy-related death. Comparisons of survival between groups were calculated from the date of randomization.

Statistical analysis. A sample of 150 patients was planned, so that an improvement in the 2-year survival from $30 \%$ (current result of surgical resection at the beginning of the trial) to $50 \%$ could be detected with a type I error $(\alpha)$ of 0.05 and a type II error $(\beta)$ of 0.1 (statistical power of 0.9 ), two-tailed probability tests being used. Statistical differences between groups were determined by Student's $t$ test, the Mann-Whitney U test, the $\chi^{2}$ test, or Fisher's exact test, where appropriate. Survival was calculated with the life table method, and differences between groups were compared with the generalized Wilcoxon test. All calculations were performed with the Statistical Package for the Social Sciences (SPSS-X version 3.1, SPSS, Inc., Chicago, Ill.).

\section{Results}

A total of 147 patients were randomized for the trial, 74 in the chemotherapy group and 73 in the control group. The patients comprised 125 men and 22 women, with a mean age (standard error of the mean [SEM]) of $64(0.8)$ years. The demographics of the two groups of patients are shown in Table I. There were no significant differences in age, sex distribution, level of tumor, tumor differentiation, and estimated stage of tumor on enrollment in the trial. 
Table I. Demography of patients on enrollment into trial

\begin{tabular}{lccc}
\hline & & No & $p$ \\
& Chemotherapy & chemotherapy & Value \\
\hline No. & 74 & 73 & - \\
Sex (male/female) & $63 / 11$ & $62 / 11$ & NS \\
Mean age (yr \pm SEM) & $64 \pm 1.1$ & $63 \pm 1.1$ & NS \\
Level of tumor & & & \\
$\quad$ Upper third & 4 & 6 & \\
$\quad$ Middle third & 61 & 61 & \\
Lower third & 7 & 5 & NS \\
$\quad$ Double level & 2 & 1 & \\
Estimation of stage of & & & \\
$\quad$ disease & 6 & 3 & \\
$\quad$ Early & 46 & 44 & NS \\
$\quad$ Moderate & 22 & 26 & \\
$\quad$ Locally advanced & & & \\
Differentiation of tumor & & 22 & \\
$\quad$ Well & 31 & 34 & NS \\
$\quad$ Moderate & 21 & 13 & \\
$\quad$ Poor & & & \\
Endoscopic length of & $5.2 \pm 0.29$ & $5.1 \pm 0.33$ & NS \\
$\quad$ tumor (cm \pm SEM) & & & \\
Barium study length of & $6.1 \pm 0.3$ & $6.3 \pm 0.27$ & NS \\
$\quad$ tumor (cm \pm SEM) & & & \\
Duration of symptom & $8.7 \pm 1.1$ & $8.5 \pm 0.9$ & NS \\
$\quad$ (wk \pm SEM) & & & \\
\hline
\end{tabular}

Figures represent number of patients unless otherwise stated. SEM, Standard error of the mean; $N S$, not significant.

Table II. Summary of treatment

\begin{tabular}{lcc}
\hline & $\begin{array}{c}\text { Chemotherapy } \\
(n=74)\end{array}$ & $\begin{array}{c}\text { No } \\
\text { chemotherapy } \\
(n=73)\end{array}$ \\
\hline $\begin{array}{l}\text { Surgery } \\
\text { Resection without chemotherapy } \\
\text { Two courses of chemotherapy } \\
\quad \text { and resection }\end{array}$ & -60 & 69 \\
$\begin{array}{l}\text { One course of chemotherapy } \\
\text { and resection } \\
\text { Bypass }\end{array}$ & $6^{*}$ & - \\
$\begin{array}{l}\text { Nonoperative } \\
\text { Two courses of chemotherapy; } \\
\text { refused surgical treatment }\end{array}$ & 1 & 4 \\
$\quad$ One course of chemotherapy; \\
stopped treatment
\end{tabular}

Figures represent number of patients.

*For details refer to text.

Treatments given to the two patient groups are listed in Table II. In the chemotherapy group, 13 patients did not adhere to the trial protocol. Of these patients, one had a complete clinical response to chemotherapy and refused surgical treatment. A small residual tumor was found, which proved to be intraepithelial carcinoma on biopsy. Tumor re-
Table III. Morbidity of preoperative chemotherapy in 74 patients

\begin{tabular}{lrrrr}
\hline & \multicolumn{4}{c}{ Grade $^{*}$} \\
\cline { 2 - 5 } & 1 & 2 & 3 & 4 \\
\hline Hematologic toxicity & 22 & 19 & 2 & 2 \\
$\quad$ Anemia & 25 & 18 & 0 & 0 \\
$\quad$ Leukopenia & 6 & 3 & 3 & 0 \\
$\quad$ Thrombocytopenia & 20 & 3 & 1 & 0 \\
Increase in serum creatinine & & \multicolumn{3}{c}{34} \\
Nausea/vomiting & \multicolumn{5}{c}{$21 \dagger$} \\
Electrolyte disturbance & \multicolumn{5}{l}{} \\
\hline
\end{tabular}

Figures represent number of patients.

${ }^{*}$ World Health Organization grading.

†One patient had life-threatening hyponatremia.

curred 1 year later and was managed with one course of chemotherapy followed by radiotherapy. The patient remained in remission 18 months later at the time of analysis. Twelve other patients did not complete the two courses of chemotherapy, six of whom did not have surgical therapy. Of these six patients, five refused further treatment and one died of a cerebrovascular accident unrelated to chemotherapy. Of the six patients who underwent surgical treatment, one was found to have pulmonary tuberculosis and another had pancytopenia; further chemotherapy was thus withheld. The other four patients did not complete the two courses of treatment because of intolerance to the side effects of chemotherapy. Altogether, 66 of the 74 patients (89\%) in the chemotherapy group underwent resection compared with 69 of 73 patients $(95 \%)$ in the control group $\left(p=\mathrm{NS}^{*}\right)$.

The prevalence of chemotherapy toxicity is shown in Table III. Only one patient had life-threatening hyponatremia. Nausea and vomiting were common but fairly well tolerated with antiemetic medications.

The 60 patients in the chemotherapy group who completed the two courses of chemotherapy plus resection were compared with 69 patients in the control group who underwent resection. The types of resections are listed in Table IV. Middle-third tumors were most prevalent, and a Lewis-Tanner esophagectomy was the most common surgical procedure. A thoracotomy was used for resection in 53 patients $(88 \%)$ in the chemotherapy group compared with $59(86 \%)$ in the control group $(p=N S)$. Curative resections were possible in 40 patients $(67 \%)$ in the chemotherapy group and in $24(35 \%)$

${ }^{*} \mathrm{NS}=$ Not significant. 
Table IV. Types of resection

\begin{tabular}{lcc}
\hline & $\begin{array}{c}\text { Chemotherapy } \\
(n=60)\end{array}$ & $\begin{array}{c}\text { No chemotherapy } \\
(n=69)\end{array}$ \\
\hline Lewis-Tanner operation & 45 & 42 \\
Three-phase esophagectomy & 7 & 15 \\
Transhiatal esophagectomy & 4 & 7 \\
Split-sternum esophagectomy & 3 & 3 \\
Esophagogastrectomy & 1 & 2 \\
\hline
\end{tabular}

Figures represent number of patients.

of the control group ( $p=0.0003$ ). Operative TNM staging is shown in Table V. Earlier T stage and N0 disease were more common in the chemotherapy group than in the control group. Perioperative morbidity and mortality are shown in Table VI. No significant differences between groups were found. All deaths but one in the chemotherapy group were due to pneumonia. This single patient had a hemothorax necessitating reexploration for hemostasis and subsequently died of pneumonia. Four of the six deaths in the control group were attributed to pneumonia. One other patient died of myocardial infarction and one patient had cerebral metastases not detected before the operation and died of this malignant disease.

Response to chemotherapy was assessed in the 60 patients who completed two courses of chemotherapy and had pathologic examination of the resected specimen. Complete pathologic response was seen in four patients, complete clinical remission in four, partial response in 27, and no response in 25. Preoperative characteristics of responders and nonresponders are compared in Table VII. Responders had an earlier stage of disease and shorter tumor length on admission than did nonresponders.

At a median follow-up time (SEM) of 17 (1.3) months, $29(48 \%)$ patients in the chemotherapy group and $50(72 \%)$ in the control group have recurrent disease $(p=0.005)$. Patterns of recurrence are shown in Table VIII. The mean times (SEM) to recurrence were 8 (1.4) months and 9.7 (1.0) months in the chemotherapy and control groups, respectively ( $p=\mathrm{NS}$ ).

Of the discharged patients, 30 patients in the chemotherapy group and 51 in the control groups had died at the time of analysis, 28 and 50, respectively, of tumor-related causes.

Actuarial analyses of survival are shown in Figs. 1 to 4 . An intent-to-treat analysis of the 147 patients enrolled in the trial showed no significant difference between the chemotherapy and control groups. Median survivals were 16.8 and 13 months, respectively
Table V. TNM staging in patients who underwent resection

\begin{tabular}{lccc}
\hline & $\begin{array}{c}\text { Chemotherapy } \\
(n=60)\end{array}$ & $\begin{array}{c}\text { No chemotherapy } \\
(n=69)\end{array}$ & $p$ Value \\
\hline T stage & & & 0.0002 \\
T0* & 4 & 0 & \\
T1 & 8 & 2 & \\
T2 & 8 & 4 & \\
T3 & 27 & 24 & \\
T4 & 13 & 39 & 0.009 \\
N stage & & & \\
N0* & 18 & 6 & \\
N1 & 42 & 61 & \\
M stage & & & \\
M0 & 60 & 09 & \\
M1 & 0 & & \\
Group staging & & 0 & \\
Stage 0* & 4 & 7 & \\
Stage I & 6 & 59 & \\
Stage IIa & 8 & & \\
Stage IIb & 5 & & \\
Stage III & 37 & & \\
\hline
\end{tabular}

Figures represent number of patients.

${ }^{*}$ Four patients had complete pathologic response on resected specimens.

Table VI. Morbidity and mortality after resection

\begin{tabular}{|c|c|c|c|}
\hline & $\begin{array}{l}\text { Chemotherapy } \\
(n=60)\end{array}$ & $\begin{array}{c}\text { No } \\
\text { chemotherapy } \\
(n=69)\end{array}$ & $p$ Value \\
\hline Blood loss $(\mathrm{ml} \pm \mathrm{SEM})$ & $795 \pm 58$ & $733 \pm 30$ & NS \\
\hline $\begin{array}{l}\text { Operating time } \\
(\min \pm S E M)\end{array}$ & $223 \pm 5.6$ & $221 \pm 5.5$ & NS \\
\hline $\begin{array}{l}\text { Postoperative trache- } \\
\text { ostomy }\end{array}$ & $10(17 \%)$ & $21(30 \%)$ & NS \\
\hline $\begin{array}{l}\text { Postoperative ventila- } \\
\text { tion }\end{array}$ & $14(23 \%)$ & $22(32 \%)$ & NS \\
\hline $\begin{array}{l}\text { Cardiovascular compli- } \\
\text { cations* }\end{array}$ & $20(30 \%)$ & $18(26 \%)$ & NS \\
\hline $\begin{array}{l}\text { Pulmonary complica- } \\
\text { tions } \dagger\end{array}$ & $10(17 \%)$ & $11(16 \%)$ & NS \\
\hline Wound infection & $4(7 \%)$ & $7(10 \%)$ & NS \\
\hline Anastomotic leakage & $3(5 \%)$ & $0(0 \%)$ & NS \\
\hline Thirty-day mortality & 0 & $4(5.8 \%)$ & NS \\
\hline Hospital mortality & $5(8.3 \%)$ & $6(8.7 \%)$ & NS \\
\hline
\end{tabular}

Figures represent number of patients (\%) unless otherwise stated. NS, Not significant.

*Cardiovascular complications include arrhythmia, heart failure, and myocardial infarction.

$\dagger$ Pulmonary complications include bronchopneumonia and respiratory failure.

$(p=0.17)$ (Fig. 1). The actuarial 2-year survivals were $44 \%$ and $31 \%$, respectively $(p=0.13)$. When the 60 patients who completed the chemotherapy course and underwent resection were compared with the 69 patients in the control group who underwent resection, the median survivals were 16.2 


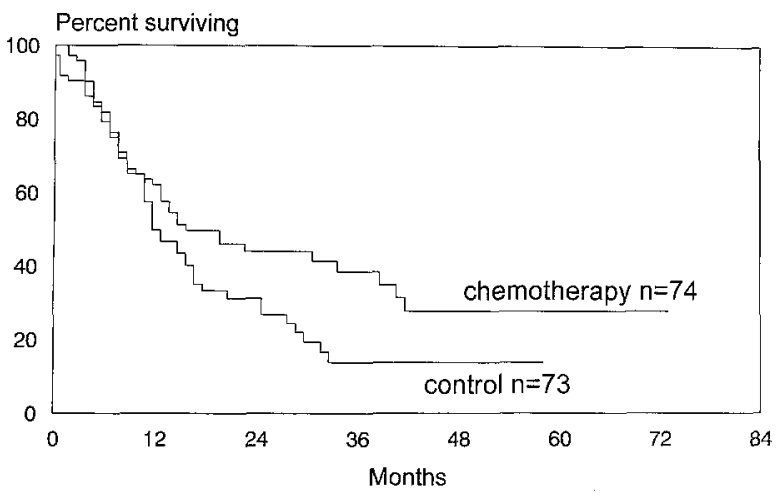

Fig. 1. Actuarial survival curves of 74 patients who had chemotherapy and 73 patients in the control group ( $p=$ 0.17 ).

Table VII. Characteristics of responders versus nonresponders

\begin{tabular}{lccc}
\hline & $\begin{array}{c}\text { Responders } \\
(n=35)\end{array}$ & $\begin{array}{c}\text { Nonresponders } \\
(n=25)\end{array}$ & $p$ Value \\
\hline Age (yr) & $64 \pm 1.6$ & $65 \pm 1.5$ & $\mathrm{NS}$ \\
Sex (male/female) & $28: 7$ & $22: 3$ & $\mathrm{NS}$ \\
Level of tumor & & & \\
$\quad$ Upper third & 1 & 3 & \\
$\quad$ Middle third & 32 & 17 & $\mathrm{NS}$ \\
$\quad$ Lower third & 2 & 4 & \\
$\quad$ Double tumor & 0 & 1 & \\
Preoperative estimate of & & & \\
$\quad$ stage of tumor & & 0 & \\
$\quad$ Early & 23 & 12 & 0.005 \\
$\quad$ Moderate & 6 & 13 & \\
$\quad$ Locally advanced & & & \\
Differentiation of tumor & 12 & 6 & \\
$\quad$ Well & 12 & 12 & NS \\
$\quad$ Moderate & 11 & 7 & \\
$\quad$ Poor & $4 \pm 0.3$ & $6 \pm 0.6$ & 0.003 \\
Endoscopic length of & & & \\
$\quad$ tumor (cm \pm SEM) & & & \\
Duration of symptoms & $7.5 \pm 1.2$ & $8.4 \pm 2.1$ & NS \\
$\quad$ (wk \pm SEM) & & & \\
\hline
\end{tabular}

Figures represent number of patients unless otherwise stated. SEM, Standard error of the mean; $N S$, not significant.

months and 13.8 months, respectively $(p=0.4)$ (Fig. 2 ). The respective median survivals for responders and control patients were 42.2 months and 13.8 months $(p=0.003)$. Nonresponders had a worse median survival ( 8.3 months) than control subjects $(p=0.03)$ (Fig. 3). Actuarial 2-year survivals for responders, control patients, and nonresponders were $59 \%, 33 \%$, and $23 \%$, respectively. The hazard ratio for control patients over responders was 1.6 (95\% confidence interval 1.2 to 2.2 ). Survival of

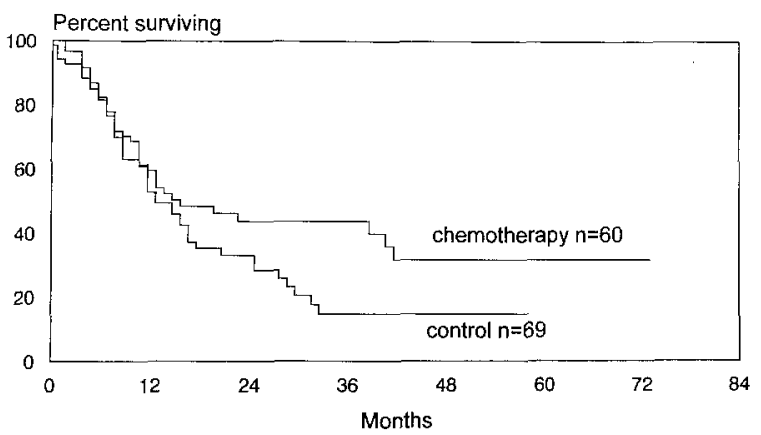

Fig. 2. Actuarial survival curves of 60 patients who completed chemotherapy and resection and 69 patients in the control group who had resection $(p=0.4)$.

Table VIII. Patterns of recurrent disease after resection

\begin{tabular}{lccc}
\hline & $\begin{array}{c}\text { Chemotherapy } \\
(n=60)\end{array}$ & $\begin{array}{c}\text { No } \\
\text { chemotherapy } \\
(n=69)\end{array}$ & $p$ Value \\
\hline No. with recurrence & 29 & 50 & 0.005 \\
Locoregional only & 7 & 21 & 0.01 \\
Distant only & 12 & 19 & 0.3 \\
Locoregional and & 10 & 10 & 0.7 \\
$\quad$ distant & & \\
\hline Figures represent number of patients. & &
\end{tabular}

patients in the chemotherapy group who had curative resections was longer than though not significantly different from that of the control group who had curative resections; median survival figures were 42 months and 28 months, respectively. When patients who had palliative resections were compared, those in the chemotherapy group had shorter survival times; median survival figures were 8 months and 13 months, respectively ( $p=0.03$ ) (Fig. 4).

\section{Discussion}

We have demonstrated in this prospective randomized controlled trial that preoperative chemotherapy was well tolerated and was not associated with increased perioperative morbidity and mortality. Significant downstaging and more apparently curative resections were possible. Chemotherapy, however, did not result in better long-term survival than surgical resection alone. Responders to chemotherapy lived significantly longer than did patients undergoing surgery alone, but at the expense of the nonresponders, whose life span was significantly shorter than that of patients undergoing surgery alone. 


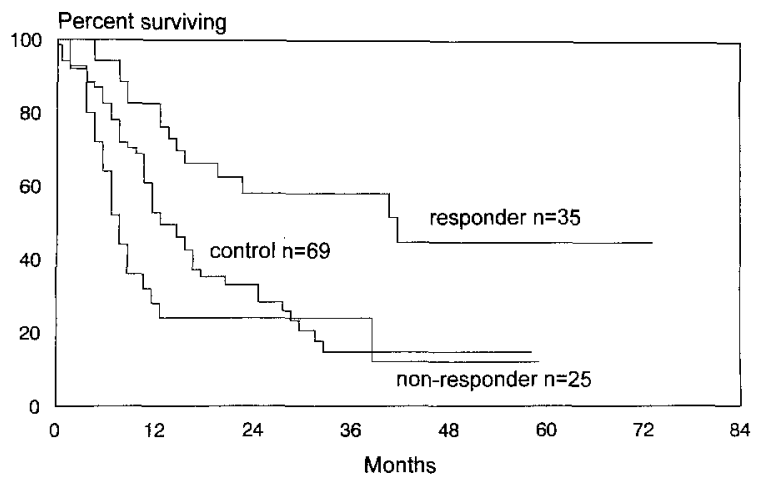

Fig. 3. Actuarial survival curves of responders, nonresponders, and control groups. Responders versus control, $p=0.003$; nonresponders versus control, $p=0.03$.

Induction chemotherapy given before surgery has theoretic advantages. Because it may improve local control, more subsequent $\mathrm{R}_{0}$ resections may be achieved. Micrometastases can also be managed, and patients who responded can be identified for postoperative adjuvant therapy. On the other hand, nonresponders would have a delay in surgical therapy and would be exposed to potentially toxic and expensive treatment.

Various phase II studies have investigated the role of preoperative chemotherapy. ${ }^{7}$ Few randomized controlled trials have been performed, and the number of patients recruited was limited. ${ }^{8-11}$ All the chemotherapeutic regimens were cisplatin based, and no cisplatin-based regimen was found to be better than another. In all four prospective randomized trials, chemotherapy was generally well tolerated and was not associated with increased perioperative morbidity and mortality. In only one study was chemotherapy associated with drug-related deaths, postoperative septic and pulmonary complications, and operation-related mortality. ${ }^{9}$ In another series one patient also died of leukopenia and sepsis. ${ }^{10}$ Overall, a major response was seen in approximately $50 \%$ of patients. Complete pathologic response was seen in fewer than $10 \%$ of patients.

In keeping with these trials, the present study showed that chemotherapy was safe and did not cause drug-related mortality. Postoperative complications were also similar. The overall response rate was 58\% (35/60), and complete pathologic response was seen in only $6.7 \%(3 / 60)$ of patients. $\mathrm{T}$ and $\mathrm{N}$ stages were downstaged to a significant degree, although the overall resectability rate was not im-

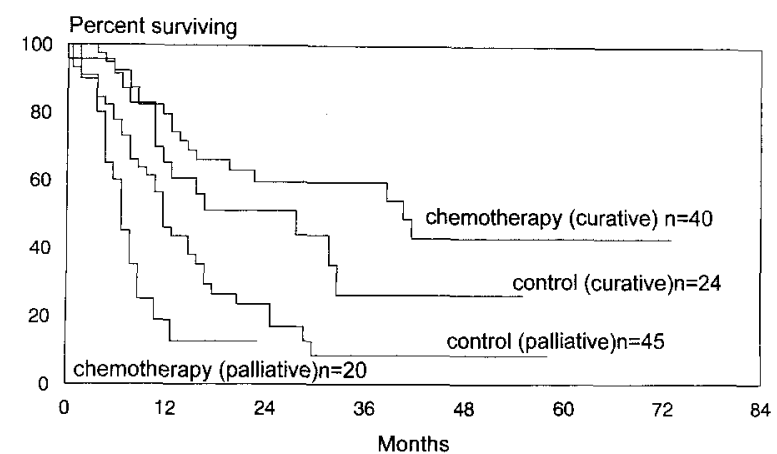

Fig. 4. Actuarial survival curves of patients with chemotherapy and control groups stratified into curative and palliative resections. Chemotherapy (curative) versus control (curative), $p=0.22$; chemotherapy (palliative) versus control (palliative), $p=0.03$.

proved over that of the control group. This could be explained by our policy of resecting even tumors of very advanced stage. The proportion of patients who underwent curative resections was significantly higher in the chemotherapy group, and in this group the survival was better, but not significantly so, than in the curative resection group without chemotherapy.

On follow-up, the recurrence rate in the chemotherapy group was significantly lower than that in the control group. The recurrence pattern suggested a significant reduction in locoregional disease. Overall, the prevalence of distant recurrences was not significantly reduced.

Overall survival advantages have not been demonstrated in the four prospective trials..$^{8-11}$ Responders to chemotherapy, however, had longer survival times. ${ }^{8-10}$ In one study, patients responding to chemotherapy had prolonged survival (median $>20$ months) when compared with either nonresponders (median 6.2 months) or patients undergoing surgical treatment only (median 8.6 months). ${ }^{8}$ The survival advantage of responders was reaffirmed in the present study. We also showed that this gain in survival was at the expense of those who did not respond to chemotherapy, whose survival was even worse than that of the control group.

The identification of responders to chemotherapy is clearly of clinical importance. Administration of chemotherapy to those who do not respond delays surgical treatment and leads to worse survival. In this study, responders had an earlier stage of disease and a shorter primary tumor. The relationship of chemoresponsiveness to earlier stage of disease was 
also suggested in another study in which a weight loss of less than $10 \%$ was significantly correlated with response. $^{8}$ Aside from clinical features, techniques of in vitro chemosensitivity testing, flow cytometric DNA analysis, and immunohistochemical staining of products of gene expression on biopsy materials have been explored as predictors of response. ${ }^{11-15}$ So far no reliable method exists that can predict responsiveness to select patients for treatment.

Our study is the largest randomized controlled series published so far on preoperative chemotherapy versus surgery alone. It includes only patients with squamous cell cancers, and it also has the advantage of being undertaken in a single institution. Single-center trials have the fewest variations in surgical and anesthetic techniques and perioperative management. Histologic assessment was also carried out by a small group of dedicated pathologists, allowing the fewest possible variations in staging method.

Multiinstitutional trials do have the advantage of recruiting sufficient numbers of patients within a short time. Two such randomized trials are in progress. The Intergroup Trial (protocol 0013) in America has accrued more than 350 patients of an intended intake of 450 . This trial compares surgery alone with three courses of cisplatin and 5-fluorouracil followed by surgery; responders then receive two more courses of chemotherapy. ${ }^{16}$ The MRC trial in the United Kingdom (protocol OE02), which planned to recruit 800 patients, has already entered 434 patients since $1992 .{ }^{17}$ It is hoped that these large-scale trials will shed more light on this important question.

Evidence is now in hand that chemotherapy given with concurrent radiotherapy is superior to chemotherapy alone in esophageal cancer. ${ }^{18}$ Up to a $40 \%$ complete response rate could be achieved, although toxicities could be substantial and distant failures remain a problem. ${ }^{19,20}$ One recent randomized trial has shown for the first time that preoperative chemoradiation resulted in a survival advantage compared with surgery alone for adenocarcinoma of the esophagus. ${ }^{21}$ So far no survival advantage could be proved for patients with squamous cell cancer. Exploring this type of multimodality treatment further, we have begun another prospective randomized trial at our institution comparing preoperative chemoradiotherapy with surgery alone.

In summary, we have shown that preoperative chemotherapy resulted in significant tumor downstaging and increased the rate of $R_{0}$ resections. A survival advantage, however, was seen only in those who had responded to chemotherapy, whose tumors were of an earlier stage. The trial did suggest a trend for survival advantage for patients who had preoperative chemotherapy. Perhaps if more patients had been recruited, a difference in comparison with the control group may have become evident. Multimodality treatment should be explored further in the form of chemoradiotherapy. It is of vital importance to have reliable predictors of response to such treatment, so that better survival can be achieved in selected patients without subjecting others to unnecessary, potentially toxic and expensive treatments.

\section{REFERENCES}

1. Earlam R, Cunha-Melo JR. Oesophageal squamous cell carcinoma. I. A critical review of surgery. Br J Surg 1980;67: 381-90.

2. Muller JM, Erasmi H, Stelzner M, Zieren U, Pichlmaier H. Surgical therapy of oesophageal carcinoma. Br J Surg 1990; 77:845-57.

3. Hermanek P. pTNM and residual tumor classifications: problems of assessment and prognostic significance. World J Surg 1995; 19:184-90.

4. Law SY, Fok M, Wong J. Pattern of recurrence after oesophageal resection for cancer: clinical implications. $\mathrm{Br} \mathrm{J}$ Surg 1996;83:107-11.

5. Kelsen DP. Adjuvant therapy of upper gastrointestinal tract cancers. Semin Oncol 1995;22:582-99.

6. Fok M, Wong J. Esophagogastrectomy for carcinoma of the abdominal esophagus and gastric cardia. In: Nyhus LM, Baker RJ, editors. Mastery of surgery. 2nd ed. Boston: Little Brown; 1992. p. 731-41.

7. Fink U, Stein HJ, Bochtler H, Roder JD, Wilke HJ, Siewert JR. Neoadjuvant therapy for squamous cell esophageal carcinoma. Ann Oncol 1994;5:517.

8. Roth JA, Pass HI, Flanagan MM, Graeber GM, Rosenberg JC, Steinberg S. Randomized clinical trial of preoperative and postoperative adjuvant chemotherapy with cisplatin, vindesine, and bleomycin for carcinoma of the esophagus. J Thorac Cardiovasc Surg 1988;96:242-8.

9. Schlag PM. Randomized trial of preoperative chemotherapy for squamous cell cancer of the esophagus. The Chirurgische Arbeitsgemeinschaft Fuer Onkologie der Deutschen Gesellschaft Fuer Chirurgie Study Group. Arch Surg 1992;127:1446-50.

10. Kok TC, Tilanus HW, Lanschot J, Siersema PD, Overhagen $\mathrm{H}$, Bosman $\mathbf{F}$, et al. Neoadjuvant chemotherapy in operable esophageal squamous cell cancer: a 3rd interim report of a randomized controlled trial. Sixth World Congress, International Society for Diseases of the Esophagus 1995. p. 139. Abstract.

11. Ancona E, Ruol A, Chiarion Sileni V, Castoro C, Santi S, Baldan N, et al. Randomized trial of combined preoperative chemotherapy versus surgery alone in operable squamous cell carcinoma of the esophagus: a preliminary report. Sixth World Congress, International Society for Diseases of the Esophagus 1995. p. 137. Abstract.

12. Kondo K, Isechi S, Akamine T, Tabira $\mathrm{Y}$, Hongo H, Okuma $T$, et al. Neoadjuvant chemotherapy for esophageal cancer 
based on chemosensitivity testing with endoscopic specimens. Fifth World Congress, International Society for Diseases of the Esophagus 1995. p. 143. Abstract.

13. Hirai T, Kawano K, Hirabayashi N, Nishiyama M, Yamashita $\mathrm{Y}$, Mukaida $\mathrm{H}$, et al. A novel in vitro chemosensitivity test using materials collected by endoscopic biopsy. Anticancer Drugs 1991;2:269-74.

14. Segalin A, Ruol A, Panozzo M, Banovina L, Bianchi LC, Peracchia A. Flow cytometric DNA analysis does not predict the radiochemoresponsiveness of esophageal cancer. J Surg Oncol 1993;54:87-90.

15. Hickey K, Grehan D, Reid IM, O'Brian S, Walsh TN, Hennessy TP. Expression of epidermal growth factor and proliferating cell nuclear antigen predicts response of esophageal squamous cell carcinoma to chemoradiotherapy. Cancer 1994;74:1693-8.

16. Ginsberg RJ. American Intergroup protocol 0113: a prospective randomized comparison of combined modality therapy for carcinoma of the esophagus-chemotherapy plus surgery versus surgery alone for patients with local regional disease. New York; 1992.
17. A randomized trial of surgery with or without pre-operative chemotherapy. Medical Research Council Newsletter. February 1996.

18. Herskovic A, Martz K, al Sarraf M, Leichman L, Brindle J, Vaitkevicius V, et al. Combined chemotherapy and radiotherapy compared with radiotherapy alone in patients with cancer of the esophagus [see comments]. $\mathrm{N}$ Engl J Med 1992;326:1593-8.

19. Kavanagh B, Anscher M, Leopold K, Deutsch M, Gaydica E, Dodge $\mathrm{R}$, et al. Patterns of failure following combined modality therapy for esophageal cancer, 1984-1990. Int J Radiat Oncol Biol Phys 1992;24:633-42.

20. MacFarlane SD, Hill LD, Jolly PC, Kozarek RA, Anderson RP. Improved results of surgical treatment for esophageal and gastroesophageal junction carcinomas after preoperative combined chemotherapy and radiation. $\mathbf{J}$ Thorac Cardiovasc Surg 1988;95:415-22.

21. Waish T, Noonan N, Hollywood D, Kelly A, Keeling N, Hennessy T. A comparison of multimodal therapy and surgery for esophageal adenocarcinoma. N Engl J Med 1996; 335:462-7.

\section{Availability of Journal back issues}

As a service to our subscribers, copies of back issues of The Journal of Thoracic and Cardiovascular Surgery for the preceding 5 years are maintained and are available for purchase from Mosby at a cost of $\$ 15.00$ per issue until inventory is depleted. The following quantity discounts are available: $25 \%$ off on quantities of 12 to 23 , and one third off on quantities of 24 or more. Please write to Mosby-Year Book, Inc., Subscription Services, 11830 Westline Industrial Drive, St. Louis MO 63146-3318, or call 800-453-4351 or 314-453-4351 for information on availability of particular issues. If unavailable from the publisher, photocopies of complete issues may be purchased from UMI, 300 N. Zeeb Rd., Ann Arbor, MI 48106, 313-761-4700. 